\title{
The differing perceptions of plastic surgery between potential applicants and current trainees: The importance of clinical exposure and electives for medical students
}

\author{
Youssef Tahiri MD CM MSc, James Lee MD CM, Jonathan Kanevsky BSc, \\ Stephanie Thibaudeau MD CM, Mirko Gilardino MD CM MSc FRCS FACS
}

Y Tahiri, J Lee, J Kanevsky, S Thibaudeau, M Gilardino. The differing perceptions of plastic surgery between potential applicants and current trainees: The importance of clinical exposure and electives for medical students. Can J Plast Surg 2013;21(3):178.

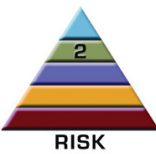
180.

BACKGROUND: Exposure to plastic surgery during medical school is

OBJECTIVE: To investigate the perceptions of Canadian medical students considering a career in plastic surgery. The results obtained were then compared with current Canadian plastic surgery residents' perceptions.

METHODS: The data were collected via two separate self-administered online surveys that were distributed to either Canadian plastic surgery residents or medical students. The questionnaires were similar and focused on three aspects: applicant details; driving force behind interest in the field; and essential character traits and competencies related to successful matching.

RESULTS: Fifty-nine plastic surgery residents and 477 medical students participated in the online survey. The most commonly reported driving forces for interest in a plastic surgery career in both groups were variety of career choice, complexity of the field, future lifestyle and enjoyable rotations in plastic surgery. Despite these similarities, the proportion of medical students and residents who opted for future lifestyle and enjoyable rotations differed in a statistically significant manner $(\mathrm{P}=0.015$ and $\mathrm{P}=0.029$, respectively). In terms of the essential competencies to match into a plastic surgery training spot, the groups differed statistically in their opinions on the relevance of intellect $(\mathrm{P}<0.001)$, manual dexterity $(\mathrm{P}<0.001)$, spatial sense $(\mathrm{P}<0.001)$ and clerkship grades $(\mathrm{P}=0.004)$.

CONCLUSION: Interested applicants should be encouraged to obtain as much elective experience as possible to assist both students in their career choice and selection committees in identifying capable applicants.

Key Words: Careers in plastic surgery; Plastic surgery residency; Selection criteria limited. Most interested applicants form their perceptions of careers in this surgical specialty during elective rotations.

Les différentes perceptions de la chirurgie plastique chez les candidats potentiels et les stagiaires : l'importance de l'exposition clinique et des stages facultatifs pour les étudiants en médecine

HISTORIQUE : L'exposition à la chirurgie plastique est limitée pendant les études en médecine. Les candidats les plus intéressés forment leurs perceptions de carrière dans cette spécialité de la chirurgie pendant leurs stages facultatifs.

OBJECTIF : Examiner les perceptions des étudiants en médecine canadiens qui envisagent une carrière en chirurgie plastique. Les résultats obtenus ont ensuite été comparés aux perceptions des résidents canadiens étudiant déjà en chirurgie plastique.

MÉTHODOLOGIE : Les chercheurs ont colligé les données au moyen de deux sondages virtuels autoadministrés distribués soit à des résidents en chirurgie plastique, soit à des étudiants en médecine du Canada. Les questionnaires étaient similaires et portaient sur trois aspects : l'information sur les candidats, les moteurs de leur intérêt dans le domaine et les principaux traits de caractère et compétences liés à un jumelage fructueux.

RÉSULTATS : Cinquante-neuf résidents en chirurgie plastique et 477 étudiants en médecine ont participé au sondage virtuel. Dans les deux groupes, une variété de choix de carrière, de complexité du domaine, de futur mode de vie et de stages agréables étaient les moteurs les plus signalés d'un intérêt pour une carrière en chirurgie plastique. Malgré ces similarités, la proportion d'étudiants en médecine et de résidents qui avaient opté pour un futur mode de vie et des stages agréables différait de manière statistiquement significative ( $\mathrm{P}=0,015$ et $\mathrm{P}=0,029$,respectivement). Pour ce qui est des compétences essentielles pour être apparié à une place de formation en chirurgie plastique, les groupes différaient statistiquement pour ce qui était de leur avis sur la pertinence de l'intellect $(\mathrm{P}<0,001)$, la dextérité manuelle $(\mathrm{P}<0,001)$, la perception spatiale $(\mathrm{P}<0,001)$ et les notes de stage $(\mathrm{P}=0,004)$.

CONCLUSION : Les candidats intéressés devraient être encouragés à obtenir le plus d'expérience de stage possible, à la fois pour les aider dans leur choix de carrière et pour aider les comités de sélection à déterminer les candidats capables.

Whe introduction of integrated plastic surgery residency pro-
grams, medical students were required to apply directly from their final year of medical school as opposed to profiting from exposure to the specialty via their core surgery training (1). For many medical schools, plastic surgery is not a regular part of the curriculum, thus limiting exposure to elective rotations. It is from these brief exposures to our specialty that interested applicants form their perceptions of careers in plastic surgery $(2-4)$.

The present study sought to investigate the perceptions of Canadian medical students considering a career in plastic surgery. To compare, the opinions of Canadian plastic surgery residents were also analyzed to determine whether the perceptions between the amateur and seasoned plastic surgery student differed.
METHODS
The data were collected via two separate online surveys consisting of 14 multiple-choice questions that were distributed to either Canadian plastic surgery residents or to Canadian medical students. The study and questionnaires were approved by the Ethics Review Board of the McGill University Health Centre (Montreal, Quebec). Each survey was prefaced by a description of the study.

The medical student questionnaire was sent to all 13 Canadian medical faculties (Figure 1). The responses of the students who expressed a career interest in plastic surgery were identified and analyzed. The resident questionnaire was sent to all Canadian plastic surgery residents (Figure 2). The questionnaires were similar and focused on three areas: applicant details (age, socioeconomic status, type of

Division of Plastic and Reconstructive Surgery, Montreal Children Hospital, McGill University, Montreal, Quebec

Correspondence: Dr Mirko Gilardino, Craniofacial Surgery, H Bruce Williams Craniofacial and Cleft Surgery Unit, Montreal Children's Hospital,

2300 Tupper Street, C11.35, Montreal, Quebec H3H 1P3. Telephone 514-412-4309, e-mail mirko.gilardino@muhc.mcgill.ca 


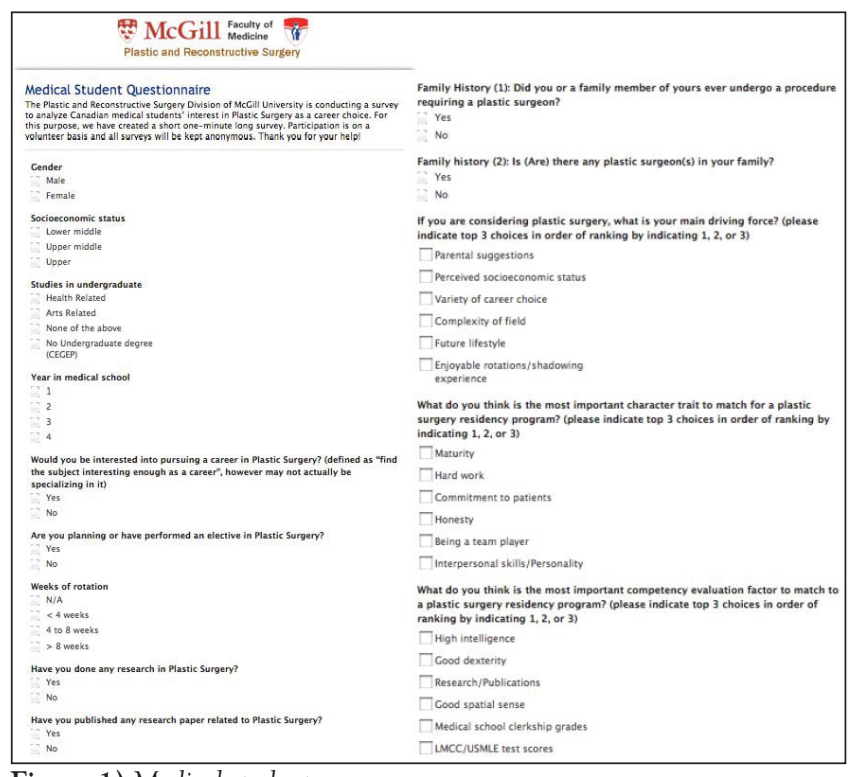

Figure 1) Medical student survey

undergraduate degree pursued, plastic surgeons in their family), driving force behind interest in the field (electives, research and publications, career details), and essential character traits and competencies related to successful matching.

Descriptive analysis of the results was performed using SPSS (IBM Corporation, USA) for Windows (Microsoft Corporation, USA) and PASW Statistics 18, release 18.0.0. Data are presented as proportions (ie, percentages). Differences in proportions were tested for significance using the $\chi^{2}$ test; $P \leq 0.05$ was considered to be statistically significant.

\section{RESULTS}

Fifty-nine plastic surgery residents (37\% respondent rate) and 477 medical students participated in the survey. The responses of the 166 medical students (39\%) who expressed a career interest in plastic surgery were analyzed.

The most commonly reported driving forces for interest in a plastic surgery career in both groups, although in slightly varying order, were variety of career choice, complexity of the field, future lifestyle and enjoyable rotations in plastic surgery (Figure 3). Despite these similarities between the groups, the proportion of medical students and residents who opted for future lifestyle and enjoyable rotations differed in a statistically significant manner $(\mathrm{P}=0.015$ and $\mathrm{P}=0.029)$, respectively).

Hard work and commitment to patient care were found to be important character traits for successful matching by both cohorts, while the groups differed statistically in the weight they placed on maturity $(\mathrm{P}<0.001)$, 'team player' attributes $(\mathrm{P}=0.046)$ and interpersonal skills $(\mathrm{P}<0.001)$. The results are represented graphically in Figure 4.

In terms of the essential competencies to match into a plastic surgery training spot, both residents and students equally believed that research productivity was important while the groups differed statistically in their opinions on the relevance of intellect $(\mathrm{P}<0.001)$, manual dexterity $(\mathrm{P}<0.001)$, spatial sense $(\mathrm{P}<0.001)$ and clerkship grades $(\mathrm{P}=0.004)$. The results are represented graphically in Figure 5.

\section{DISCUSSION}

Despite the potentially limited clinical exposure to our field, the survey demonstrated that medical students interested in applying to a plastic surgery residency program generally shared their reasons for applying with those actually training in the field (ie, residents). That is, complexity of the field and variety of career choice were shared by both cohorts, both potential applicants and residents currently in training, as major driving factors for interest in plastic surgery.

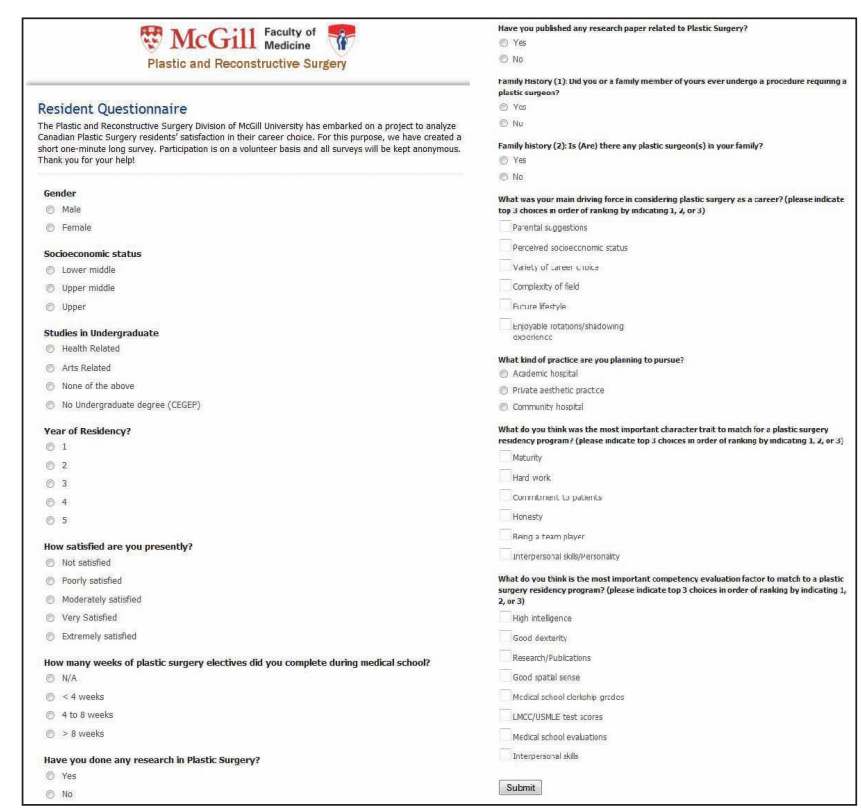

Figure 2) Resident survey

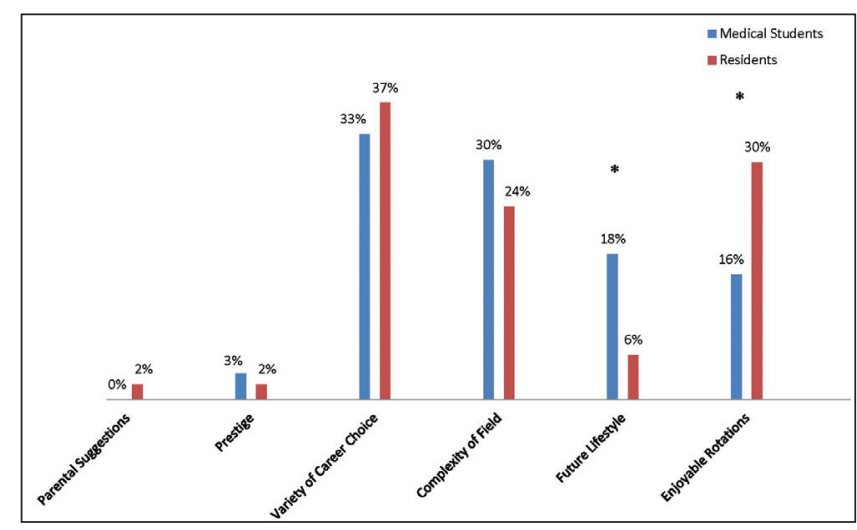

Figure 3) Medical student and resident survey results of the most important driving force for choosing plastic surgery. ${ }^{*}$ Statistically significant (ie, $P<0.05$ )

Interestingly, however, the groups differed in the weight they placed on the 'expected lifestyle' of a career in plastic surgery in a statistically significant way. Eighteen per cent of the medical student respondents noted that future career lifestyle was the driving force behind their choice, contrasting with only $6 \%$ of plastic surgery residents $(\mathrm{P}=0.015)$. The latter is a potentially important misconception among applicants to plastic surgery. For the initiated, there is no question that plastic surgery residency is extremely labour intensive when the academic learning requirements, research demands and operative training are considered collectively $(2-4)$. It is the belief of the authors that the idea of a plastic surgery career incorporating a well-balanced lifestyle may be the perceived ideal model for many applicants. Although this career model is certainly possible, residents soon become acquainted with the time commitments associated with complex reconstructive (multidisciplinary) care, administrative responsibilities, academic duties and research associated with a university appointment. These responsibilities often need to be balanced with the time and financial pressures of operating a private practice, which for many academic surgeons falls outside the hospital environment and work hours. For the interested medical student who completes one or two elective rotations before applying to plastic surgery, all of this may transpire into an unexpected reality of the career during residency $(3-5)$. 


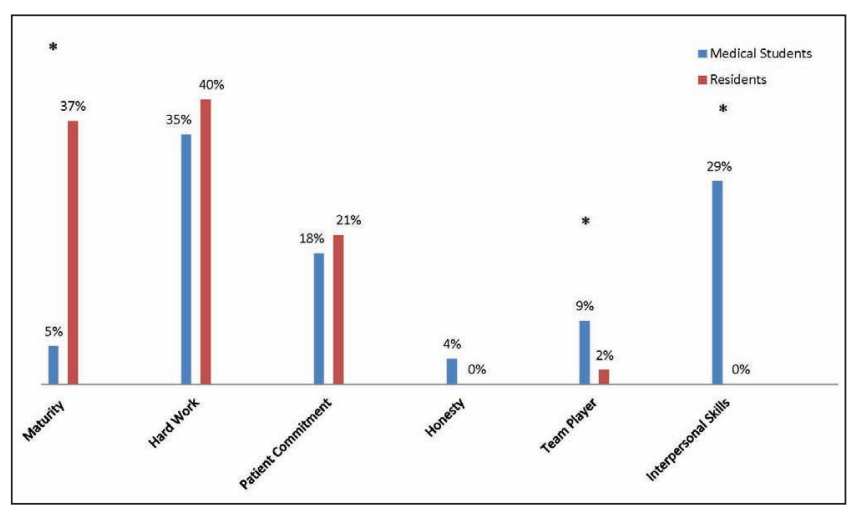

Figure 4) Medical student and resident survey results of the most commonly reported character trait needed for applicants to successfully match to plastic surgery residency programs. *Statistically significant (ie, $P<0.05$ )

Resident respondents also noted that elective rotations (ie, direct clinical experience in plastic surgery) were integral in spurring interest in plastic surgery more often than within the group of students interested in the field - again, a difference that was statistically significant $(\mathrm{P}=0.029)$. When one analyzes the surprisingly high proportion (39\%) of the 477 surveyed medical students who expressed an interest in plastic surgery - a proportion that likely is higher than the actual percentage of students who have completed an elective in plastic surgery - one can surmise that some of the interest in the field is partially presumptive, rather than based on direct clinical experience.

In an informative survey published by Nguyen and Janis (6) in 2012, the authors noted that residents accepted through the independent program (after general surgery training) had lower attrition rates compared with integrated plastic surgery resident positions. In addition, $78 \%$ of medical students entering general surgery internships progressed to change pathways, highlighting the high chance that medical students may change their mind when accepted directly into a specialty. Previous exposure and success within a surgical specialty, such as general surgery, and increased exposure to plastic surgery rotations during this core training are all believed to improve the selection of qualified applicants to the specialty. Despite the advantages of an independent path of admission to plastic surgery, the integrated path is gradually becoming the mainstream method of training across Canada and the United States. To that end, we, as plastic surgery educators, must encourage interested applicants to obtain as much elective experience as possible to both assist students in their career choice and selection committees in identifying capable applicants (7-9).

Limitations to the present study include the descriptive nature of the data and the potential for bias within the groups. We chose to examine the opinion of medical students who expressed an interest in the field of plastic surgery. This group was chosen to represent the opinion of applicants to our residency positions with varying but obviously limited degrees of exposure to the field. These results were contrasted with residents already enrolled in plastic surgery training, who have had significantly more exposure to the field, the residency and its commitments, and the attending staff.

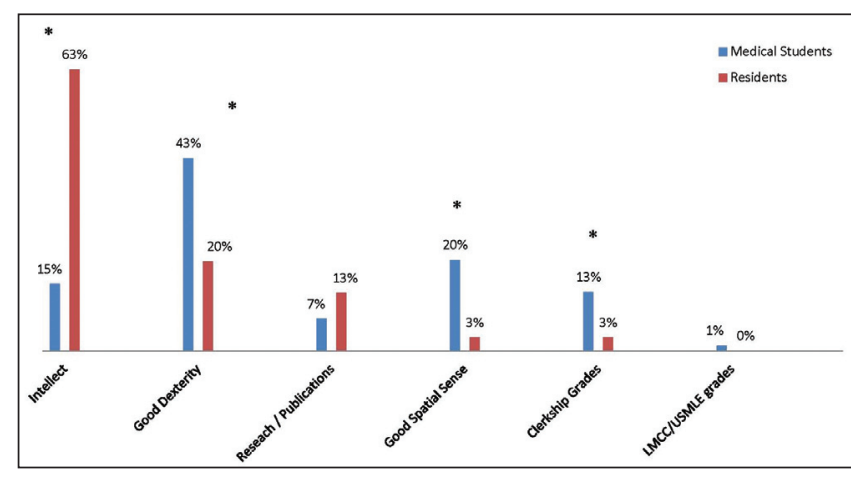

Figure 5) Medical student and resident survey results of the most important competencies needed to successfully match applicants to plastic surgery residency programs. *Statistically significant (ie, $P<0.05$ )

\section{CONCLUSION}

Because the integrated path is gradually becoming the mainstream method of training across Canada and the United States, interested applicants should be encouraged to obtain as much elective experience as possible to both assist the students in formulating an accurate representation of being a plastic surgeon, in appropriately selecting their career choice and aiding selection committees in identifying capable applicants.

DISCLOSURES: The authors have no financial disclosures or conflicts of interest to declare. All authors participated in the research, and have reviewed and agree with the content of the article.

\section{REFERENCES}

1. Granick MS, Blair PG, Sachdeva AK. A new educational role for plastic surgery in the fourth year of medical school. Plast Reconstr Surg 1999;103:1523-8.

2. Rohrich RJ. The making of a plastic surgeon: Present and future. Plast Reconstr Surg 2003;111:1289-90.

3. Rohrich RJ. Training the generation X plastic surgeon:

Dispelling the myths? Plast Reconstr Surg 2001;108:1733-4.

4. Rohrich RJ, Weber RA. Are teachers born or do they develop over time? Plast Reconstr Surg 2012;129:1209-11.

5. Rohrich RJ. Professionalism: The end product of the medical profession. Plast Reconstr Surg 2006;118:1487-8.

6. Nguyen AT, Janis JE. Resident selection protocols in plastic surgery: A national survey of plastic surgery independent program directors. Plast Reconstr Surg 2012;130:459-69.

7. Janis JE, Hatef DA. Resident selection protocols in plastic surgery: A national survey of plastic surgery program directors. Plast Reconstr Surg 2008;122:1929-39.

8. LaGrasso JR, Kennedy DA, Hoehn JG, Ashruf S, Przybyla AM. Selection criteria for the integrated model of plastic surgery residency. Plast Reconstr Surg 2008;121:121e-5e.

9. Rogers CR, Gutowski KA, Munoz-Del Rio A, et al. Integrated plastic surgery residency applicant survey: Characteristics of successful applicants and feedback about the interview process. Plast Reconstr Surg 2009;123:1607-17. 